\title{
Effectiveness of Implementing Traffic Rules and Regulations Regarding Republic Act 10586 in Cabanatuan City
}

\author{
Mary Chris Austria-Cruz \\ maria_cristi@yahoo.com \\ Nueva Ecija University of Science and Technology Philippines \\ *Corresponding author: Mary Chris Austria-Cruz:maria_cristi@yahoo.com
}

Received 05 January 2020; $\quad$ Accepted 12 January 2020;

Published 16 January 2020

\section{ABSTRACT}

The Land Transportation Office (LTO) has an ADDA provision which is known as the Anti-Drunk and Drugged Driving Act of 2013 or R.A 10586. This is where the part of the service standards and regulations of LTO came from. Anti-Drunk and drugged driving act of 2013 is an Act penalizing person's driving under the influence of alcohol, dangerous drugs, and other similar substances. And for other purposes, it means that this republic act aims to reduce and prevent vehicular accident, loss of life and damage to property and this study also aims to determine the effectiveness of Implementation of Anti-Drunk and Drugged Driving Act of 2013 of how does it affects the driver and the society.

After conducting the research procedure, the researcher found out that in Implemented Rules and Regulation, the Motorist/Drivers and the LTO Enforcers described it as being often obey and well performed of their duties and responsibilities regarding R.A 10586, but there is significance difference between the response of both respondents.

However, the findings of this study have led the researcher in determining the effectiveness of implementing traffic rules and regulation and awareness of the Motorist/Drivers in driving of the said Implemented Rules and Regulations.

Keywords: R.A. 10586, Anti-Drunk and Drugged Driving Act, Driving, Implemented Rules and Regulation, Land Transportation Office, Awareness

\section{INTRODUCTION}

The Land Transportation Office (LTO) has an ADDA provision which is known as the Anti-Drunk and Drugged Driving Act of 2013 or R.A 10586. As a result of road traffic collisions stated by Redhwan and Karim (2010), road traffic accidents are described as fatal or non-fatal injuries. Koushki and Al-Ghadeer (1992) found and indicated that the driver's problem of failing to comply with traffic control measures is far greater than that in urban areas. In order to prevent this public health catastrophe, Gopalakrishnan (2012) concluded that knowledge formation, stringent enforcement of traffic rules and practical infrastructure steps are the need for the hour.

Anti-Drunk and drugged driving act of 2013 is an Act penalizing person's driving under the influence of alcohol, dangerous drugs, and other similar substances. Thus the World Health Organization (2019) reported that the Anti-Drunk and Drugged Driving Act of 2013 only focused on penalizing alcoholinfluenced drivers but did not cover any rehabilitation provision.
The aim of the Republic Act No. 10586 is to reduce and prevent vehicular accident, loss of life and damage to property. However, Cruz (2013) concluded that the legislature has to enforce Implementing Rules and Regulations for Republic Act No. 10586 To limit the wide latitude for police officers. Savolainen and Mannering (2007) also concluded that wearing a helmet eliminates $\mathrm{MC}$ riders ' injuries in the event of collisions.

According to Seva (2017), Drunk driving, non-use of helmets and underestimating the speed of the oncoming vehicle when overtaking are significant predictors of serious injury. Kleiman et al. (2018) claimed that stoned driving may be avoided by making it a traffic violation - again, assuming proper accuracy testing - and by actively spreading anti-stoned driving messaging to cannabis consumers, many of whom actually do not think stoned driving is risky.

\section{CONCEPTUAL FRAMEWORK}

This study is anchored to and base on Republic Act No. 10586 or the Anti-Drunk and Drugged Driving Act of 2013. Which aims to 
improve the efficiency in the delivery of government service to the public by reducing traffic accident or vehicular accident and to prevent damage property and an injury to the person or loss of life. It also concerns with the determination of the effectiveness of its implementation. Drunk and drugged driving because life loss to the person and is listed in the top five causes of death in the Philippines.

\section{OBJECTIVES OF THE STUDY}

The study described the Implemented Rules and Regulations of R.A. No. 10586 be determined to prevent the violation Drunk and Drugged Driving and the significant difference on the response of LTO Officers and Motorists/drivers in determining the Implementation of Rules and Regulations of RA 10586 to prevent the violation of Drunk and Drugged Driving.

\section{HYPOTHESIS OF THE STUDY}

There is no significant difference on the response of LTO Officers and Motorists/drivers in determining the Implementation of Rules and Regulations of RA 10586 to prevent the violation of Drunk and Drugged Driving

\section{METHODOLOGY}

This study used the descriptive method. The researchers used the structured questions form to determine perception or view of the respondents regarding this topic. Descriptive Method is designed for the researcher to gather information about presenting existing conditions and to describe the nature of the situation as it exists at the time of the study and to explore the causes of particular phenomena. (Camic et al., 2003)

\section{RESULTS}

Table 1 showed that when it comes to Implementing Rules and Regulations of R.A. 10586 the (1) Strictly implemented traffic rules and regulations (R.A 10586), (2) Caught traffic violators that not complying with the safety measures while riding a motor vehicle (e.g. not wearing helmets, not wearing seatbelts), (3) Seized traffic violators without a valid driver's license, (4) Confined traffic violators under the influence of alcohol/liquor, (5) Apprehended traffic violators that intoxicated of drug, all these items of LTO officers as often which means that the LTO Officers strictly implementing traffic rules and regulations R.A. 10586.

Table:1. Implementing rules and regulations of R.A 10586 (LTO Officials)

\begin{tabular}{|c|l|l|}
\hline Statement & WM & VI \\
\hline $1 . \quad$ Strictly implemented traffic rules and regulations(R.A 10586) & 5 & Always \\
\hline $\begin{array}{l}\text { Caught traffic violators that not complying with the safety measures while riding a motor } \\
\text { vehicle(e.g. not wearing helmets, not wearing seatbelts). }\end{array}$ & 4 & Often \\
\hline 3. Seized traffic violators without a valid driver`s license. & 4.06 & Often \\
\hline 4. $\quad$ Confined traffic violators under the influence of alcohol/liquor. & 2.88 & Average \\
\hline 5. Apprehended traffic violators that intoxicated of drugs. & 2.41 & Sometimes \\
\hline Total Weighted Mean & 3.67 & Often \\
\hline
\end{tabular}

Table 2 showed that when it comes to implemented rules and regulations of this Republic Act, the (1) I follow the traffic rules and regulations regarding Anti-Drunk and Drugged Driving Act of 2013, (2)I comply with the safety measures in riding motor vehicle (e.g. helmets, safety pads, seatbelts), (3) I drive with a valid driver`s license, (4)I drive without a valid driver`s license, (5) I drive with a registered motor vehicle, (6) I drive even if I am under the influence of alcohol/liquor, (7) I drive while under the intoxication of drugs, all these items of Motorist/Drivers as average which means that the Motorist/Drivers are adequately obeying the traffic rules and regulations of R.A. 10586 because some motorist/drivers not abiding the traffic rules and regulations.

Table:2. The Implemented Rules and regulations of R.A. 10586 (Motorist/Driver)

\begin{tabular}{|r|l|l|}
\hline Statement & WM & VI \\
\hline 1. I follow the traffic rules and regulations regarding Anti-Drunk and Drugged Driving Act of 2013. & 4.59 & Always \\
\hline 2. I comply with the safety measures in riding motor vehicle (e.g. helmets, safety pads, seatbelts). & 4.31 & Always \\
\hline 3. I drive with a valid driver`s license. & 4.1 & Often \\
\hline 4. I drive without a valid driver`s license. & 1.78 & Never \\
\hline 5. I drive with a registered motor vehicle & 4.09 & Often \\
\hline 6. I drive even if I am under the influence of alcohol/liquor. & 1.85 & Sometimes \\
\hline 7. I drive while under the intoxication of drugs. & 1.14 & Never \\
\hline Total weighted mean & 3.12 & Average \\
\hline
\end{tabular}

Table 3 showed that based on the computation using T-test: Twosample assuming unequal variance, the computed value of 2.21346146 as compared to critical value of 2.10981556 , we may conclude that our Null hypothesis should be rejected. Therefore, there is significant difference on the response of LTO Officers and Motorists/drivers in determining the Implementation of Rules and Regulations of RA 10586 to prevent the violation of Drunk and
Drugged Driving. This supports by the statement of some of the drivers/motorists saying that they are not driving while under the influence of alcohol/liquor or drugs or any other substances but in the side of the LTO Officers they apprehend some motorist/drivers that are under the influence of alcohol/liquor or drugs or any substances. 
Table:3. Significant difference on the response of LTO Officers and Motorists/drivers in determining the Implementation of Rules and Regulations of RA 10586 to prevent the violation of Drunk and Drugged Driving

\begin{tabular}{lll}
\hline & LTO & Motorists/Driver \\
\hline Mean & 3.67058824 & 3.124761905 \\
Variance & 1.01470588 & 0.16800347 \\
Observations & 17 & 150 \\
Hypothesized & Mean & \\
Difference & 0 & \\
Df & 17 & \\
t Stat & 2.21346146 & \\
P(T<=t) one-tail & 0.02041394 & \\
t Critical one-tail & 1.73960672 & \\
P(T<=t) two-tail & 0.04082787 & \\
t Critical two-tail & 2.10981556 & \\
\hline
\end{tabular}

\section{CONCLUSIONS}

Under item Implementing Rules and Regulations there are 6 out of 17 LTO Officers describe the R.A 10586 as being always executed well by the said LTO Officers while 5 out of 17 describe as often executed and some 4 out of 17 described it as average and the rest 2 out of 17 described it as sometimes.

Under the Implemented Rules and Regulations there are 43 out of 150 Motorist/Drivers describe the R.A 10586 is being often executed well by the said Motorist/Drivers while 90 out of 150 describe as average executed and rest 17 out of 150 described it as sometimes was being executed.

There is significant difference on the response of LTO Officers and Motorists/drivers in determining the Implementation of Rules and Regulations of RA 10586 to prevent the violation of Drunk and Drugged Driving.

\section{Data Availability}

All relevant data are within the paper and its supporting information files.

\section{Conflicts of Interest}

The author declared that there is no conflict of interest regarding the publication of this paper.

\section{Funding Statement}

The author didn't receive any specific funding for this work.

\section{REFERENCES}

[1] Camic, P. M., Rhodes, J. E., \& Yardley, L. E. (2003). Qualitative research in psychology: Expanding perspectives in methodology and design. American Psychological Association.

[2] Cruz, E. R. P. (2013). Undue Influence: The Sobriety of the Presumption of Regularity Doctrine in the Determination of the" Under the Influence of Alcohol" Requirement in the Anti-Drunk and Drugged Driving Act of 2013. Ateneo Law Journal, 58(2).

[3] Gopalakrishnan, S. (2012). A public health perspective of road traffic accidents. Journal of family medicine and primary care, $1(2), 144$

[4] Kleiman, M. A., Jones, T., Miller, C. J., \& Halperin, R. (2018). Driving while stoned: Issues and policy options. Journal of Drug Policy Analysis, 11(2).

[5] Koushki, P. A., \& Al-Ghadeer, A. M. (1992). Driver noncompliance with Traffic regulations in rapidly developing urban areas of Saudi Arabia. Transportation research record, 1-1.

[6] Redhwan, A. A., \& Karim, A. J. (2010). Knowledge, attitude and practice towards road traffic regulations among university students, Malaysia. Int Med J Malaysia, 9(2), 29-34.

[7] Republic Act No. 10586 (2013). An act penalizing persons driving under the Influence of Alcohol, Dangerous Drugs, and Similar Substances, and for other purposes (Ph.)

[8] Savolainen, P., \& Mannering, F. (2007). Probabilistic models of motorcyclists' injury severities in single-and multi-vehicle crashes. Accident Analysis \& Prevention, 39(5), 955-963.

[9] Seva, R. R. (2017). Modeling Motorcycle Accident Severity in the Philippines using Helmet use, Riding experience, and Driving behaviour. International Journal for Traffic and Transport Engineering, 7(3).

[10] World Health Organization. (2019). Global status report on alcohol and health 2018. World Health Organization. 